\title{
MODELO MULTICRITÉRIO DE DECISÃO COM FOCO NA LOGÍSTICA HUMANITÁRIA A PARTIR DE MEDIDAS DE DESEMPENHO PARA ABRIGOS TEMPORÁRIOS
}

Manuela Marques Lalane Nappi, Dra . (UFSC); João Carlos Souza, Dr. (UFSC)

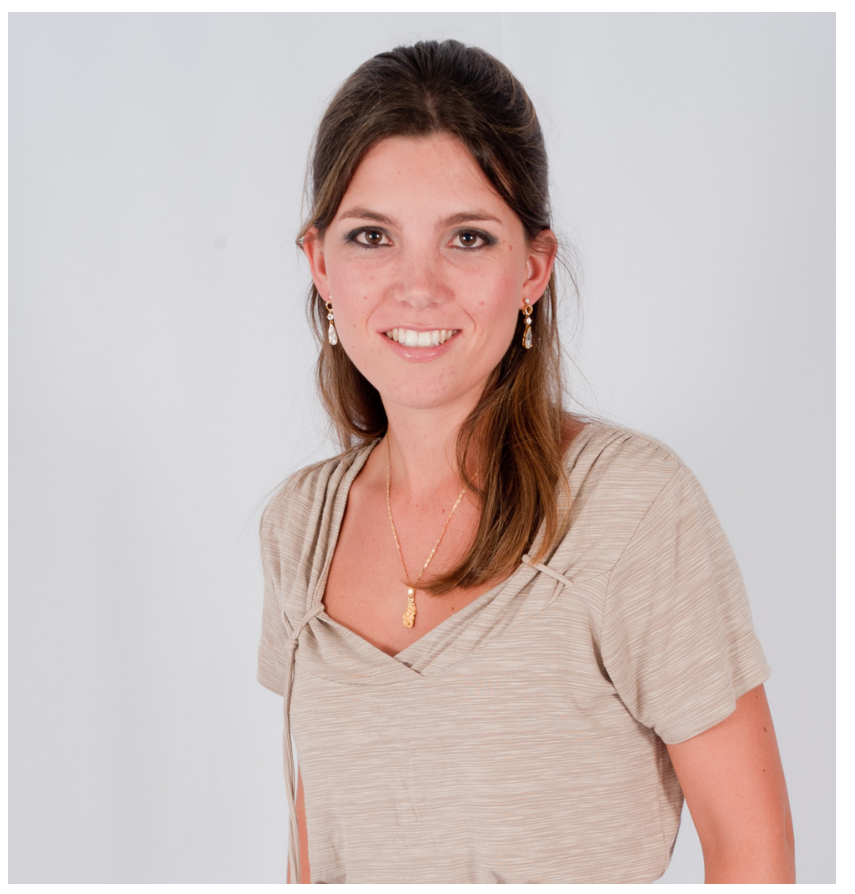

Manuela Marques Lalane Nappi

A ocorrência de desastres naturais ou antrópicos, no Brasil e no mundo, vem evidenciando um tratamento logístico especial, designado de logística humanitária. Sabe-se, no entanto, que existem grandes desafios na implementação de processos logísticos sistematizados, especialmente aqueles relacionados à infraestrutura e localização de centrais de assistência humanitária e coordenação de processos, incluindo-se os abrigos temporários.

O objetivo deste trabalho foi o desenvolvimento de um modelo multicritério de decisão, com foco nos princípios da logística humanitária, para a seleção e localização espacial de abrigos temporários comunitários ou coletivos (abrigos provisórios em espaços internos). Por abordarem objetivos que requerem uma visão global e abrangente, os métodos multicritérios mostram-se eficazes na gestão do risco. Uma das suas principais características está no fato de reconhecerem a subjetividade como parte intrínseca dos problemas de decisão.

O modelo multicritério proposto neste trabalho foi possível a partir do desenvolvimento de um sistema de medição de desempenho, constituído por um conjunto de indicadores que ajudam a verificar o alcance, ou não, de determinados objetivos. Cabe destacar que este estudo se centrou nas preferências de especialistas em logística, bem como na revisão de documentos publicados por organizações de ajuda humanitária e de outras literaturas específicas. Foram levantados e hierarquizados nove possíveis critérios, ou critérios globais, com seus respectivos subcritérios, ou critérios locais que, por sua vez, podem ser avaliados a partir de seus aspectos relevantes, também denominados indicadores de desempenho. Lapidada a hierarquia foram determinadas as intensidades, ou prioridades, dos critérios globais e locais. Isso possibilitou a determinação da importância de cada elemento em relação ao objetivo geral. A estruturação do sistema, a organização dos dados e a análise dos critérios avaliados foram realizadas no software Expert Choice, que se utiliza do método de análise multicritério Analytic Hierarchic Process (AHP).

O modelo multicritério para seleção de abrigos temporários teve como base a priorização de critérios globais, locais e seus indicadores e foi denominado ShelterPro. A averiguação do sistema de medição de desempenho desenvolvido deu-se a partir da verificação da consistência das avaliações de especialistas e a aplicabilidade do modelo multicritério de decisão resultante foi demonstrada a partir da simulação de possíveis cenários. O ShelterPro foi desenvolvido com o intuito de ser um software de plataforma intuitiva, uma ferramenta de fácil compreensão e usabilidade.

Como resultado, portanto, foi estabelecido um sistema de avaliação de abrigos temporários comunitários ou coletivos, sendo que o modelo multicritério de decisão 
originado desse sistema, além de permitir a análise individual de cada abrigo, constitui uma ferramenta multicritério de apoio à decisão no que se refere à seleção e localização de abrigos temporários. Acredita-se que essa ferramenta possa ser útil no nível estratégico ou operacional das decisões logísticas. No nível estratégico relaciona-se à acumulação de infraestruturas, neste caso especificamente de abrigos temporários, auxiliando na determinação da quantidade de abrigos necessária diante de diferentes cenários de desastres. Consequentemente, será possível apontar a necessidade de novas estruturas para a constituição de abrigos, bem como as modificações e adaptações necessárias para que elas atinjam um desempenho melhor. No nível operacional, o modelo multicritério de apoio à decisão poderá ser utilizado na distribuição da população afetada entre os abrigos selecionados e instituídos.

Figura 1: Tela oferecida pelo software com a indicação de um evento e com a localização de abrigos temporários cadastrados

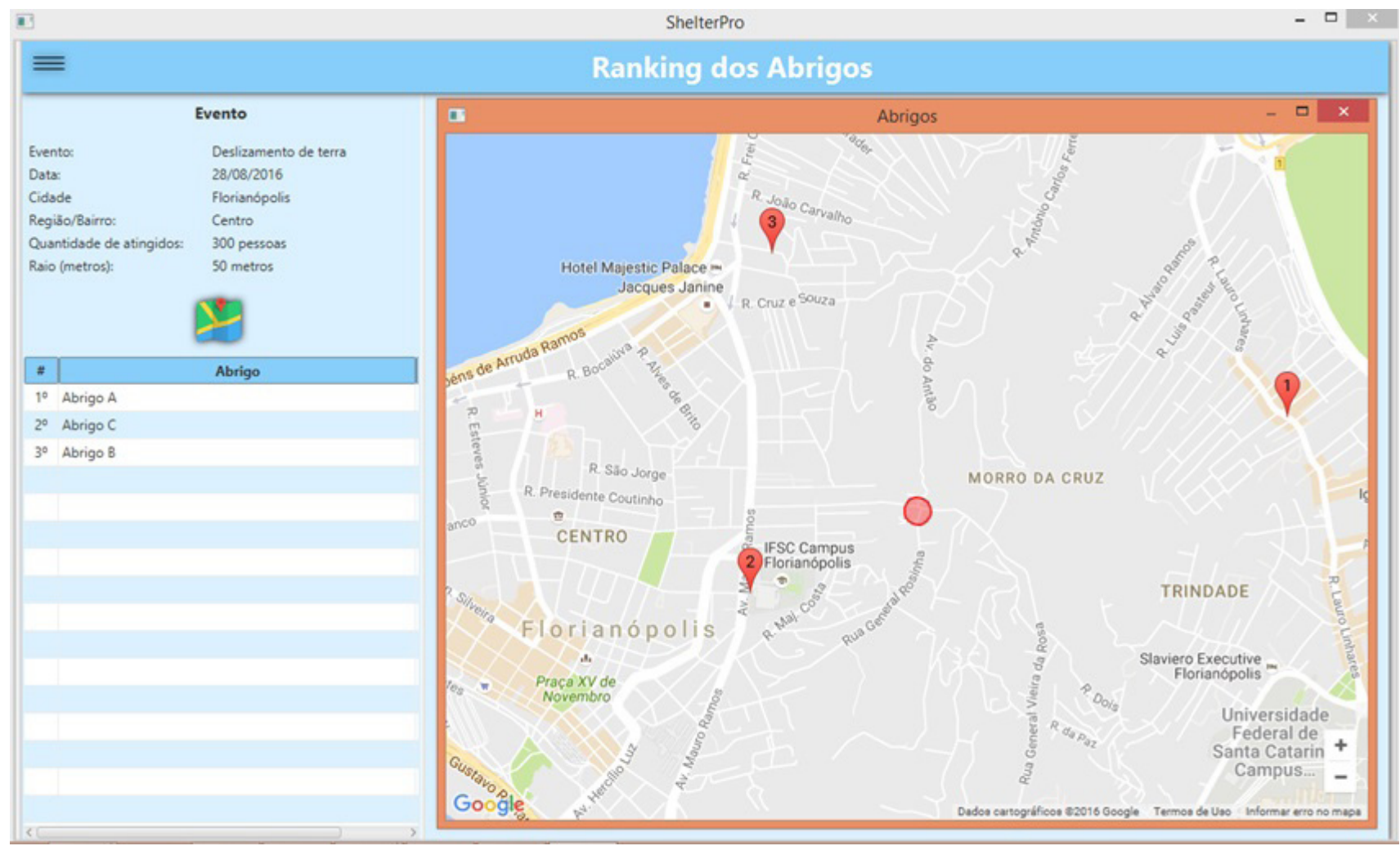

Fonte: Imagem obtida por captura de tela do software ShelterPro, de autoria conjunta (Arq. Manuela Nappi e Eng. Autom. Raphael Santos). 